American Journal of Animal and Veterinary Sciences 5 (2): 102-106, 2010

ISSN $1557-4555$

(C) 2010 Science Publications

\title{
Oral Administration of Gelatin Hydrolysate Reduces Clinical Signs of Canine Osteoarthritis in a Double-Blind, Placebo-Controlled Trial
}

\author{
${ }^{1}$ A.C. Beynen, ${ }^{2}$ H.W. Van Geene, ${ }^{2}$ H.V. Grim, ${ }^{2}$ P. Jacobs and ${ }^{2}$ T. Van der Vlerk \\ ${ }^{1}$ Vobra Special Petfoods BV, Veghel, The Netherlands \\ ${ }^{2}$ University of Applied Sciences HAS Den Bosch,'s Hertogenbosch, The Netherlands
}

\begin{abstract}
Problem statement: There are indications that the intake of gelatin hydrolysate has a beneficial impact on the clinical signs of osteoarthritis in dogs. Data from a controlled trial were required to substantiate these indications. Approach: A double-blind, placebo-controlled trial with privately owned dogs was carried out to assess the efficacy of a preparation of gelatin hydrolysate in the treatment of osteoarthritis. With the use of a questionnaire, the clinical signs were evaluated by the owners. For a period of 8 weeks, the test dogs daily received $10 \mathrm{~g}$ of gelatin hydrolysate; as a placebo, soya protein isolate was used. The supplements were mixed with the diet; all dogs were fed on the same dry food. There were 15 dogs per treatment group. Results: The administration of gelatin hydrolysate significantly improved activity (vitality) and significantly reduced stiffness and lameness. Conclusion: Gelatin hydrolysate is commonly used as a component of human foods and is generally considered as safe. It is suggested that a dose of about $2.5 \%$ in a dry food would be beneficial for dogs with osteoarthritis.
\end{abstract}

Key words: Dog, osteoarthritis, gelatin, hydrolysate

\section{INTRODUCTION}

Canine osteoarthritis is a joint disease commonly seen in veterinary practice. In severe conditions, the symptoms are chronic pain, lameness and disability. Osteoarthritis is a degenerative and inflammatory condition in which there is a loss of cartilage matrix associated with a release of pro-inflammatory cytokines. Osteoarthritis cannot be cured and management aims at the relief of pain through reduction of inflammatory reactions and further breakdown of cartilage. Current treatment involves the use of NonSteroidal Anti-Inflammatory Drugs (NSIADS) to decrease inflammation and consequently pain, but side effects such as vomiting and diarrhea may occur. There are various nutraceuticals on the market that are promoted as safe, effective compounds to manage canine osteoarthritis. They are administered as supplements or incorporated into industrially produced dog foods. However, the efficacy of the generally applied nutraceuticals can be questioned. Reviews of the efficacy show that inappropriate experimental designs were used and/or equivocal results were obtained (Aragan et al., 2007; Beynen, 2008; Budsberg and Bartges, 2006; Henrotin et al., 2005).

Gelatin hydrolysate is a purified, enzymaticallytreated protein derived from collagen in bone and skin of swine and cattle. The protein has a typical and unique amino acid composition in that it is very rich in glycine, proline and hydroxyproline. In an open study without a placebo treatment, Weide (2004) reported a positive effect of gelatin hydrolysate in dogs with osteoarthritis. Because of the open nature of the study and the absence of a placebo group, the observed decrease in lameness cannot be taken as evidence for a beneficial effect of gelatin hydrolysate. It is very likely that placebo effects occur when evaluating the clinical signs of dogs with osteoarthritis (Dobenecker et al., 2002; Gingerich and Strobel, 2003; Innes et al., 2003; Pollard et al., 2006).

This study readdresses the efficacy of a preparation of gelatin hydrolysate in the treatment of canine osteoarthritis. In a double-blind, placebo-controlled trial, privately owned dogs were used and the clinical signs were evaluated by the owners. For a period of 8 weeks, the test dogs daily received $10 \mathrm{~g}$ of gelatin hydrolysate, which was mixed with their diet. As a placebo, soya protein isolate was used. All dogs were fed on the same dry food. Part of the results have been published elsewhere in abstract form (Beynen, 2009).

\section{MATERIALS AND METHODS}

Animals: Dogs with signs of osteoarthritis were recruited through various types of announcements and by approaching breed associations, veterinarians and

Corresponding Author: A.C. Beynen,Vobra Special Petfoods BV, Veghel, The Netherlands 
acquaintances. The (potential) participants were informed about the purpose and design of the trial and had to sign a statement on informed consent. Forty one dogs were subjected to either the placebo or test group. Three dogs did not finish the trial and the trial questionnaires for another 8 dogs were not complete so that the data for 30 dogs (15 per treatment group) were available for analysis. Table 1 shows the characteristics of the dogs as based on the intake questionnaire completed by their owners. There was a wide variety of dog breeds, the major ones being Golden Retrievers $(n=3)$, Rottweilers $(n=3)$, Border Collies $(n=3)$ and others $(n=21)$. The analgetics used were as follows: Metacam $(n=3), \quad$ Rimadyl $(n=6)$, Cortafen forte $(n=2)$ and others $(n=2)$. The following supplements were used: Primeval $(n=3)$ and others $(n=6)$. The owners were instructed to continue as usual without or with the administration of analgetic and/or supplement during the course of the trial.

Experimental design: Recruitment of the dogs, maintaining contact with the dog owners, supplying of food and supplements, data collection and general coordination of the trial was done by $\mathrm{HWvG}$ and $\mathrm{HVG}$, who were both blinded to treatment modality. The eligible dogs were allocated to either the placebo or treatment group by ACB, who kept the treatment code closed until statistical analysis of the data. Allocation was done so that the distribution of the severity of lameness, as based on the intake questionnaire, would be similar among the two groups. To exclude any influence of the diet, all dogs were fed on the same complete dry food (Casa-Fera Adult, Vobra Special Petfoods BV, Veghel, The Netherlands), which was supplied in blank packaging. The food was sent by courier to the dog owners together with the supplement. The placebo supplement was soya protein isolate (Nurish $\AA$ 1500, The Solae Company). The test supplement was soya protein isolate mixed with gelatin hydrolysate (Rousselot ${ }^{\circledR}$ ADF, Vion Ingredients) in a 1:1 (w/w) ratio. The gelatin hydrolysate was mixed with soya protein hydrolysate to mask its characteristic, flowing property. The supplements were provided in a blank container together with a measuring spoon. The owners were instructed to mix three full spoons of the supplement $(20 \mathrm{~g})$ with the dog food once a day. The trial lasted 10 weeks. The first two weeks served as a baseline. During the first week the dogs were gradually transferred from their habitual diet to the food supplied. During the second week only the food supplied was fed. Then, for a period of 8 weeks, the food supplied and the experimental supplement were administered.

Trial questionnaire: The trial questionnaire was in the form of a booklet, which also provided instructions. The severity of the signs of osteoarthritis was scored by the owners by marking with a cross a $10-\mathrm{cm}$, horizontal line. The line was without any unit, but functioned as a scale in combination with the description. The signs to be scored by owners were: activity (vitality), stiffness, swelling of joint, lameness, paralysis, pain. Body condition was also scored. The signs were scored on day 0 (start) and weekly afterwards.

To aid in scoring the signs, the following descriptions were given:

Activity (vitality): How active and vital is your dog? Is your dog capable of playing? Does your dog reach the door earlier than you? Is your dog excited when you are taking her/him somewhere?" The scale ran, from "Not active" (left) to "Very active" (right).

Stiffness: "How stiff is your dog? Does your dog easily get out of its basket in the morning or does it take time to get started when going for a walk?". The scale ran, from "Very stiff" (left) to "Smooth" (right).

Swelling of joint: "Does your dog have swelling on the site of osteoarthritis? Around the joint with diagnosed osteoarthritis, there may be swelling of either a tough or soft nature". The scale ran from "Marked swelling" (left) to "No swelling" (right).

Lameness: "Is your dog lame or does it not use one leg at all? Watch your dog carefully to ascertain whether or not there is a change of the degree of lameness during the trial". The scale ran from "Very lame" (left) to "Not lame" (right).

Table 1: General characteristics of the dogs

\begin{tabular}{lll}
\hline Characteristic & Placebo group $(\mathrm{n}=15)$ & Gelatin hydrolysate $(\mathrm{n}=15)$ \\
\hline Osteoarhritis diagnosed by veterinarian, yes/no & $12 / 3$ & $12 / 3$ \\
Mean age, years (range) & $8.0(2-13)$ & $7.9(2-13)$ \\
Mean body weight, $\mathrm{kg}$ (range) & $33.0(8-73)$ & $31.8(6-68)$ \\
Gender, female/male & $8 / 7$ & $3 / 12$ \\
Use of analgetics, yes/no & $8 / 7$ & $7 / 8$ \\
Use of supplements, yes /no & $4 / 11$ & $5 / 10$ \\
\hline
\end{tabular}


American J. Animal \& Vet. Sci., 5 (2): 102-106, 2010

Table 2: Baseline values and changes over time in the osteoarthritic signs (improvement is indicated by a + sign) and body condition

\begin{tabular}{|c|c|c|c|c|c|}
\hline \multirow[b]{2}{*}{ Variable } & \multicolumn{2}{|c|}{ Placebo group $(\mathrm{n}=15)$} & \multicolumn{2}{|c|}{ Gelatin hydrolysate $(\mathrm{n}=15)$} & \multirow{2}{*}{$\begin{array}{l}\mathrm{p} \text {-value for group } \\
\text { difference in change }\end{array}$} \\
\hline & Baseline & Change & Baseline & Change & \\
\hline Activity & 4.51 & -0.03 & 5.54 & +1.32 & 0.022 \\
\hline Stiffness & 3.89 & +0.42 & 4.89 & +1.80 & 0.047 \\
\hline Swelling & 8.36 & +0.09 & 8.95 & +0.07 & 0.939 \\
\hline Lameness & 6.06 & +0.23 & 5.80 & +1.68 & 0.015 \\
\hline Paralysis & 9.11 & +0.00 & 8.77 & +0.16 & 0.526 \\
\hline Pain & 7.57 & +0.10 & 7.46 & +1.02 & 0.130 \\
\hline Body condition & 4.43 & +0.23 & 4.67 & +0.01 & 0.536 \\
\hline
\end{tabular}

Paralysis: "Does your dog show signs of paralysis? Sometimes, osteoarthritis can lead to paralysis. The dog usually wobbles its hind body and has difficulty rising". The scale ran from "Hind body fully paralyzed" (left) to "No paralysis" (right).

Pain: "Does the osteoarthritis cause pain in your dog? Does your dog growl or scream when she/he gets up or makes a wrong movement. Does your dog indicate pain or does she/her try to bite you when touching certain joints". The scale ran from "Usually an expression of pain" (left) to "Never an expression of pain" (right).

Body condition: "What is the body condition of your dog? In an obese dog, the ribs are not visible and are covered by a layer of fat tissue. In addition, the belly is not slimmer than the chest and thus shows no waist. A dog with normal body condition has ribs that are just visible and shows a waist. A skinny dog has pronounced ribs". The scale ran from "Very skinny" (left) to "Very fat" (right).

Data analysis: The marked scales were transferred into values by using the distance, expressed in $\mathrm{cm}$, of the crosses from the left side $(=0 \mathrm{~cm})$. To calculate the baselines, the values for day 0 , week 1 and week 2 were averaged per variable per dog. To calculate the final values, those for weeks 8-10 were averaged. For each dog and each variable, the change over time was calculated. To identify treatment effects, the changes over time for the placebo and test group were subjected to the Student's $t$ test with $\mathrm{p}<0.05$ as criterion of statistical significance.

\section{RESULTS}

Table 1 shows that the general characteristics of the placebo and test group were similar, except for the gender distribution. The baseline values for activity and stiffness were higher in the test group than in the placebo group, pointing at less severe signs in the former group (Table 2). When compared to the placebo treatment, the oral administration of gelatin hydrolysate significantly improved the signs of activity (vitality), stiffness and lameness (Table 2). There also was a numerical decrease in pain sensation that failed to reach statistical significance. Body condition was not affected by treatment (Table 2).

\section{DISCUSSION}

Taking the stand that gelatin hydrolysate is effective in the treatment of canine osteoarthritis should be based on a likely mechanism of action and the observation that in double-blind clinical trials it provokes a significantly better effect than a placebo. The latter prerequisite is met by the present trial, but reproducibility needs to be demonstrated. The oral administration of gelatin hydrolysate significantly improved the signs of activity (vitality), stiffness and lameness. On a scale from 0-10, the improvements were $1.35,1.38$ and 1.45 , respectively, after correction for the placebo effect. The corrected decrease in pain amounted to 0.92 . The observation on lameness supports that of Weide (2004) in an open, noncontrolled trial. In that trial, 20 dogs received $20 \mathrm{~g}$ of gelatin hydrolysate daily, in addition to their habitual diet. After 4 months there was a decrease in the severity of lameness, the score falling from an initial value of $1.73-0.84$ on a $0-4$ scale. The magnitude of that effect, when transformed to a $0-10$ scale is similar to that seen in this study, indicating that $10 \mathrm{~g}$ of gelatin hydrolysate per day would be equally effective as $20 \mathrm{~g}$. As mentioned above, the trial of Weide (2004) by itself cannot be taken as evidence for a beneficial effect of gelatin hydrolysate. However, the current data and those of Weide (2004) taken together do point at efficacy of gelatin hydrolysate in the treatment of canine osteoarthritis. It should be noted that studies in human patients with osteoarthritis also have shown a reduction in pain and functional improvement after oral administration of gelatin hydrolysate (Barnett et al., 1998; Moskowitz, 2000).

For the use of gelatin hydrolysate in the treatment of canine osteoarthritis to have a scientific basis, it should be possible to explain in molecular terms how it 
inhibits inflammation and/or inhibits breakdown of the cartilage matrix. Collagen in the cartilage matrix and gelatin hydrolysate have a similar amino acid composition. Research in mice has demonstrated that after oral administration of radiolabeled gelatine hydrolysate the radioactivity was specifically found in cartilage (Oesser et al., 1999). There are indications that the amino acids in gelatin hydrolysate stimulate the synthesis of collagen cartilage (Lippiello et al., 1977). The decrease in the severity of lameness in the study of Weide (2004) was associated with increased blood concentrations of glycine, proline and hydroxyproline and a lowering of the plasma content of Matrix Metalloproteinase-3 (MMP-3). MMP-3 is involved in the degradation of collagen molecules in the cartilage matrix. It could thus be suggested that the positive effect of gelatin hydrolysate is caused, at least in part, by inhibition of the degradation of collagen in the cartilage matrix. Possibly, inhibition of cartilage breakdown is associated with a reduction in inflammation and pain sensation.

The clinical signs of the dogs were evaluated by their owners which had been instructed equally and carefully. It has been reported that the owners' evaluation of osteoarthritic signs in dogs correspond well with those of veterinarians (Innes et al., 2003). Further aspects also indicate that the present observations are not biased. The double-blind nature of the trial excluded any observer bias. Furthermore, the baseline values for activity and stiffness of the test dogs were higher than those of the controls. The higher values point at less severe clinical signs so that the treatment-induced improvement cannot be ascribed to treatment-independent regression to the mean. The general characteristics of the two groups were similar so that allocation bias is unlikely. Changes in body weight are associated with changes in the severity of canine osteoarthritis (Kealy et al., 1997; Impellizeri et al., 2000; Mlacnik et al., 2006). During the course of this study, body condition of the dogs remained constant in both treatment groups so that the positive effect of gelatine hydrolysate on osteoarthritis can be considered independent of body weight.

\section{CONCLUSION}

The observed, statistically significant improvement of clinical signs in dogs with osteoarthritis can be considered of clinical relevance. Gelatin hydrolysate is commonly used as component of human foods and is generally considered as safe. Within the European Union, the use of gelatin hydrolysate from either ruminant or non-ruminant origin is approved for incorporation into the feed of all species. In this study, dogs weighing on average $32 \mathrm{~kg}$ were given $10 \mathrm{~g}$ of gelatin hydrolysate per day. The dogs would require about $450 \mathrm{~g}$ of dry food daily for maintenance. Gelatin hydrolysate is heat stable and can be added to dog food prior to extrusion. This study indicates that a dose of about $2.5 \%$ in a dry food would be beneficial for dogs with osteoarthritis.

\section{REFERENCES}

Aragan, C.L., E.H. Hofmeister and S.C. Budsberg, 2007. Systematic review of clinical trials of treatments for osteoarthritis in dogs. J. Am. Veter. Med. Assoc.., 230: 514-521. PMID: 17302547

Barnett, M.L., J.M. Kremer, E.W. St Clair, D.O. Clegg and D. Furst et al., 1998. Treatment of rheumatoid arthritis with oral type II collagen: Results of a multi-center, double-blind, placebo-controlled trial. Arthrit. Rheumat., 41: 290-297. PMID: 9485087

Beynen, A.C., 2008. Optimalisering van een dieetvoeder voor honden met osteartrose. Dier-enArts, 23: 16-21.

Beynen, A.C., 2009. A dietary treatment for osteoarthritis. Petfood Industry, Nov. 28-32.

Budsberg, S.C. and J.W. Bartges, 2006. Nutrition and osteoarthritis in dogs: Does it help? Vet. Clin. North Am. Small Anim. Pract., 36: 1307-1323. PMID: 17085237

Dobenecker, B., Y. Beetz and E. Kienzle, 2002. A placebo-controlled double-blind study on the effect of nutraceuticals (chondroitin sulfate and mussel extract) in dogs with joint disease as perceived by their owners. J. Nutr., 132: 1690S-1691S. PMID: 12042495

Gingerich, D.A. and J.D. Strobel, 2003. Use of clientspecific outcome measures to assess treatment effects in geriatric, arthritic dogs: Controlled clinical evaluation of a nutraceutical. Vet. Therapeut., 4: 56-66. 12756636

Henrotin, Y., C. Sanchez and M. Balligand, 2005. Pharmaceutical and nutraceutical management of canine osteoarthritis: Present and future perspectives. Vet. J., 170: 113-123. PMID: 15993795

Impellizeri, J.A., M.A. Tetrick and P. Muir, 2000. Effect of weight reduction on clinical signs of lameness in dogs with osteoarthritis. J. Am. Vet. Med. Assoc., 216: 1089-1091. PMID: 10754668

Innes, J.F., C.J. Fuller, E.R. Grover, A.L. Kelly and J.F. Burn, 2003. Randomized, double-blind, placebo-controlled parallel group study of P54FP for the treatment of dogs with osteoarthritis. Vet. Record 152: 457-460. PMID: 12723628 
Kealy, R.D., D.F. Lawler, J.M. Ballam, G. Lust and G.K. Smith et al., 1997. Five-year longitudinal study on limited food consumption and development of osteoarthritis in coxofemoral joints of dogs. J. Am. Vet. Med. Assoc., 210: 222-225. PMID: 9018356

Lippiello, L., D. Hall and J. Mankitt, 1977. Collagen synthesis in normal osteoarthritic human cartilage. J. Clin. Invest., 59: 593-600. PMID: 845251

Mlacnik, E., B.A. Bockstahler, M. Muller, M.A. Tetrick, R.C. Nap and J. Zentek, 2006. Effects of caloric restriction and a moderate or intense physiotherapy program for treatment of lameness in overweight dogs with osteoarthritis. J. Am. Vet. Med. Assoc., 229: 1756-1760. PMID: 17144822

Moskowitz, R.W., 2000. Role of collagen hydrolysate in bone and joint disease. Seminars Arthrit. Rheumat., 30: 87-99. PMID: 11071580
Oesser, S., M. Adam, W. Babel and J. Seifert, 1999. Oral administration of ${ }^{14} \mathrm{C}$ labeled gelatin hydrolysate leads to an accumulation of radioactivity in cartilage of mice $(\mathrm{C} 57 / \mathrm{BL})$. J. Nutr., 129: 1891-1895. PMID: 10498764

Pollard, B., W.G. Guilford, K.L. Ankenbauer-Perkins and D. Hedderley, 2006. Clinical efficacy and tolerance of an extract of green-lipped mussel (Perna canaliculus) in dogs presumptively diagnosed with degenerative joint disease. N. Zealand Vet. J. 54: 114-118. PMID: 16751841

Weide, N., 2004. The use of gelatin hydrolyzate in clinical orthopedic healthy dogs and dogs with chronic musculoskeletal disorders. Ph.D. Thesis. Tierärztliche Hochschule Hannover. 